\title{
An Innovative Coalitional Trading Model for a Biomass Power Plant Paired with Green Energy Resources
}

\author{
Hooman Khaloie, Jean-François Toubeau, Member, IEEE, François Vallée, Member, IEEE, Chun Sing Lai, Senior \\ Member, IEEE, and Loi Lei Lai, Life Fellow, IEEE
}

\begin{abstract}
The role of biomass resources to diminish the dependency on fossil fuels is steadily increasing worldwide. More importantly, governments set goals to boost the share of renewable energy resources in the power sector to face up to global warming issues. In this paper, a coalitional game model for the trading of a Biomass Power Plant (BPP) paired with a concentrating solar power facility and a wind park is proposed. In the proposed coalitional trading architecture, the physical coupling between biomass and concentrating solar power facilities is embedded, while cost sources related to operation and maintenance of all units as well as harvesting and transportation of forestry residue are taken into account to represent a more pragmatic trading approach. The suggested coalitional trading model is formulated as a stochastic model with three sequential stages. Moreover, game theory concepts, i.e., $\tau$-value, nucleolus, and Shapleyvalue, are exploited and compared for profit allocation to the coalition members. A cost-benefit analysis is also conducted to investigate the effect of cooperative and non-cooperative trading models on the BPP's investment feasibility. The results highlight the lucrativeness of the proposed coalitional trading model and remarkable reduction in the payback period of the BPP under a cooperative game framework.
\end{abstract}

Index Terms-Biomass Power Plant (BPP), cooperative game, cost-benefit analysis, electricity markets, profit allocation.

\section{NOMENCLATURE}

$\begin{array}{ll}\text { Abbreviations } & \\ \text { BCS } & \text { Biomass-Concentrating Solar. } \\ \text { BPP } & \text { Biomass Power Plant. } \\ \text { IRR } & \text { Internal Rate of Return. } \\ \text { NPV } & \text { Net Present Value. } \\ \text { Sets and Indices } \\ i & \text { Index of coalition members, } i=1, \ldots, n . \\ \mathcal{T} & \text { Set of time slots, indexed by } t . \\ \Omega & \text { Set of scenarios, indexed by } \omega \text { and } \breve{\omega} . \\ \text { Parameters } & \\ c^{\mathrm{BP}} / c^{\mathrm{CS}} / c^{\mathrm{W}} & \begin{array}{l}\text { Variable operation and maintenance costs of } \\ \text { biomass/ concentrated solar/ wind plant }(€ / \mathrm{MWh}) .\end{array} \\ c^{\mathrm{H}} / c^{\mathrm{Tr}} & \begin{array}{l}\text { Harvesting/ transportation cost of forestry residue } \\ (€ / \mathrm{o} . \mathrm{d}) \text { ). }\end{array} \\ G_{t, \omega}^{\mathrm{F}} / G_{t, \omega}^{\mathrm{W}} & \begin{array}{l}\text { Predicted output power of solar field/ wind park } \\ (\mathrm{MW}) .\end{array}\end{array}$

H. Khaloie, J.-F. Toubeau, and F. Vallée are with the Power Systems and Markets Research Group, University of Mons, Mons, Belgium.

C. S. Lai (corresponding author) is with the Brunel Interdisciplinary Power Systems Research Centre, Department of Electronic and Electrical Engineering Brunel University London, London, UB8 3PH, U.K (e-mail: chunsing.lai@brunel.ac.uk).

L. L. Lai is with the Department of Electrical Engineering, School of Automation, Guangdong University of Technology, Guangzhou 510006, China. $o_{t, \omega}^{+} / o_{t, \omega}^{-} \quad$ Coefficient related to upward/ downward imbalance.

$K \quad$ Daily available forestry residue (o.d.t).

$\overline{P^{\mathrm{pb}}} / \overline{P^{\mathrm{W}}} \quad$ Maximum generation limit of the powerblock/ wind park (MW).

$q_{0}^{\Xi} \quad$ Initial state of charge of the thermal energy storage (MWh)

$q^{\mathrm{STU}} \quad$ Amount of power needed to power-up the BCS $\overline{Q^{b}} \quad$ powerblock (MW).

$\overline{Q^{\mathrm{b}}}, Q^{\mathrm{b}} \quad$ Upper/ lower bound of generated power by $\overline{Q^{p b}} Q^{p b} \quad$ biomass-fired boiler (MW).

$\overline{Q^{\mathrm{pb}}}, Q^{p b} \quad$ Upper/ lower bound of injected power to the powerblock (MW).

$\overline{Q^{\Xi}}, \underline{Q^{\Xi}} \quad$ Maximum/ minimum state of charge of the thermal energy storage (MWh)

$\Gamma \quad$ Discount rate (or rate of return).

$\Delta \quad$ Coefficient related to restricting power sold to or purchased from the adjustment market.

$\eta_{1}, \eta_{2} \quad$ Conversion efficiency of powerblock/ biomass-fired boiler

$\lambda_{t, \omega}^{\mathrm{A}} / \lambda_{t, \omega}^{\mathrm{D}} \quad$ Price of adjustment/ day-ahead market ( $€ / \mathrm{MWh}$ ).

$\mu \quad$ Mean of the normal distribution (€/MWh).

$\pi_{\omega} \quad$ Scenario probability.

$\varpi^{\text {down }} / \varpi^{\text {up }}$ Ramping-down/ Ramping-up bound of the powerblock (MW/hr).

$\sigma \quad$ Standard deviation of the normal distribution (€/MWh).

$\overline{\varsigma^{\mathrm{ch}}} / \overline{\varsigma^{\text {dis }}} \quad$ Upper bound of charge/ discharge of the thermal energy storage (MW).

$\chi \quad$ Heating value of forestry residue (MWh/o.d.t).

$\digamma_{t} \quad$ Net cash flows $(€)$.

Variables

$k_{t, \omega} \quad$ Amount of forestry residue fed into biomass-fired boiler (o.d.t).

$\mathcal{M}_{i}(v) \quad$ Utopia point of coalition member $i(€)$.

$p_{t, \omega}^{\mathrm{A}, \mathrm{BC}} \quad$ Amount of power sold by BCS plant in adjustment market (MW).

$p_{t, \omega}^{\mathrm{A}, \mathrm{W}^{\prime}} / p_{t, \omega}^{\mathrm{A}, \mathrm{W}^{\prime \prime}}$ Amount of power sold/ purchased by wind plant in perter (MW).

$p_{t, \omega}^{\mathrm{D}, \mathrm{BC}} / p_{t, \omega}^{\mathrm{D}, \mathrm{W}}$ Amount of power sold by BCS/ wind plant in dayahead market (MW).

$p_{t, \omega}^{\mathrm{pb}} \quad$ Electric power output of the BCS powerblock (MW).

$p_{t, \omega}^{\mathrm{Sch}} \quad$ Arranged electric power of the coalition (MW).

$p_{t, \omega}^{\mathrm{y}, \mathrm{b}} / p_{t, \omega}^{\mathrm{y}, \mathrm{f}} / p_{t, \omega}^{\mathrm{z}}$ Portion of electric power produced by biomass-fired boiler/ solar field/ thermal energy storage [MW].

$q_{t, \omega}^{\mathrm{b}} \quad$ Generated power of the biomass-fired boiler (MW).

$q_{t, s}^{\mathrm{pb}} \quad$ Thermal power input to the powerblock (MW).

$q_{t, \omega}^{\stackrel{\Xi}{\Xi}} \quad$ State of charge of the thermal energy storage

(MWh).

$q_{t, \omega}^{\mathrm{y}, \mathrm{b}} / q_{t, \omega}^{\mathrm{y}, \mathrm{f}} / q_{t, \omega}^{\mathrm{z}}$ Amount of thermal power conveyed from biomassfired boiler/ solar field/ thermal energy storage to 


\begin{tabular}{|c|c|}
\hline$q_{t, \omega}^{\mathrm{x}, \mathrm{b}}, q_{t, \omega}^{\mathrm{x}, \mathrm{f}}$ & $\begin{array}{l}\text { Amount of thermal power conveyed from biomass- } \\
\text { fired boiler and solar field to the thermal energy } \\
\text { storage (MW). }\end{array}$ \\
\hline $\mathcal{R}_{i}(v)$ & Minimum right vector of coalition member $i(€)$. \\
\hline $\mathcal{R} \mathcal{M}_{i}(\mathcal{S})$ & $\begin{array}{l}\text { Remainder of coalition member } i \text { in coalition } \mathcal{S} \\
(€) \text {. }\end{array}$ \\
\hline$u_{i}(v)$ & Profit allocated to coalition member $i(€)$ \\
\hline$V(\mathcal{S})$ & $\begin{array}{l}\text { Profit built via the alternation of coalition members } \\
(€) \text {. }\end{array}$ \\
\hline$v(\mathcal{I}) / v(\mathcal{S})$ & Profit gained in grand coalition/ coalition $\mathcal{S}(€)$ \\
\hline$y_{i}(v)$ & $\begin{array}{l}\text { Profit allocation imputation to coalition member } i \\
(€) \text {. }\end{array}$ \\
\hline$\alpha_{t}^{\mathrm{b}} / \alpha_{t}^{\mathrm{pb}}$ & $\begin{array}{l}1 \text { if biomass-fired boiler/ powerblock is on, } 0 \\
\text { otherwise. }\end{array}$ \\
\hline$\beta_{t}$ & $\begin{array}{l}1 \text { if the BCS powerblock starts-up at hour } t, 0 \\
\text { otherwise. }\end{array}$ \\
\hline$\gamma_{t}^{\mathrm{ch}} / \gamma_{t}^{\mathrm{dis}}$ & $\begin{array}{l}1 \text { if thermal energy storage is in charge/ discharge } \\
\text { mode, } 0 \text { otherwise. }\end{array}$ \\
\hline$\epsilon_{t, \omega}^{+} / \epsilon_{t, \omega}^{-}$ & $\begin{array}{l}\text { Deviation of the coalition from its settled schedule } \\
\text { when it is operating long/ short (MW). }\end{array}$ \\
\hline$\varepsilon_{t, \omega}^{1} / \varepsilon_{t, \omega}^{2} / \varepsilon_{t, u}^{3}$ & $\begin{array}{l}\text { Revenue of the coalition from first-/ second-/ third- } \\
\text { stage of the decision framework }(€) \text {. }\end{array}$ \\
\hline$\vartheta(i)$ & Profit gained through individual trading model. \\
\hline$\Phi_{t, \omega}^{\mathrm{BP}} / \Phi_{t, \omega}^{\mathrm{CS}}$ & Total cost of biomass/ concentrated solar plant $(€)$. \\
\hline
\end{tabular}

\section{INTRODUCTION}

\section{A. Motivation and Literature Survey}

D URING the past decade, tremendous attention has been paid to biomass, wind, and solar energy sources as proper alternatives to fossil fuels for tackling global warming issues [1]. In this context, the European Union set a goal to attain more than $80 \%$ emission mitigation by 2050 compared to 1990 by concentrating on renewable energy sources [2]. To this end, many fossil fuel-based electric power technologies must be substituted with renewable power plants like Biomass Power Plants (BPPs), concentrating solar power facilities, and wind parks. With the growing emergence of these renewable technologies in the electric power sector, these resources' trading problem in electricity markets has been turned into an underlying issue [3].

The trading problem for the aforementioned renewable resources singly or jointly with other technologies has been studied from different perspectives in previous works [4]-[18]. Concerning the wind parks' trading problem, a joint day-ahead energy and reserve trading model by taking into account the confidence level of real-time reserve deployment for a wind park was proposed in [4]. In [5], a risk-based decision-making framework for optimal trading of a wind park founded on the second-order stochastic dominance constraints was developed. The day-ahead trading problem for a wind plant having energy transactions with demand response providers was studied in [6]. Efforts were made in [7], [8] to present propitious trading models for concentrating solar power facilities. In both [7], [8], the trading problem for a sole concentrating solar power facility was provided, while authors in [7] focused on the trading in day-ahead energy, reserve, and regulation markets, but on the other hand, the trading model proposed in $[\overline{8}]$ centered on the day-ahead energy market. In contrast with the vast research on the trading of wind parks and concentrating solar power facilities, limited works emphasized the BPP's trading problem
[9], [10]. In [9], a stochastic trading approach for a BPP aiming to derive day-ahead and real-time participation strategies was suggested. A bidding strategy structure for a combined heat and power unit taking advantage of a biomass-fired boiler in the day-ahead market was studied in [10].

Several trading models in the literature concentrated on the coordinated trading of at least two electric power technologies jointly [11]-[18]. A look-ahead trading pattern for wind and concentrating solar power facilities considering a two-day bidding horizon was presented in [11]. In [12], wind parks, responsive loads, and battery energy storage units were considered as a single entity participating in day-ahead and intraday markets. The trading behavior of a hybrid producer, including renewable energy resources, responsive loads, and compressed air energy storage, was discussed in [13]. In [14], a multi-objective trading model was developed for a BPP and a concentrating solar power facility in the dayahead and adjustment markets. In all models suggested in [11]-[14], the lack of a profit-sharing mechanism for different entities is seen. By contrast, some efforts were made to exploit profit allocation mechanisms in the coordinated trading of diverse energy resources [15]-[18]. Leveraging nucleolus and Shapley-value approaches, the profit allocation for the joint trading of wind and power-to-gas technologies was addressed in [15]. A Nash bargaining theory for profit allocation between wind and concentrating solar power facilities was proposed in [16]. The profit allocation approach between demandside resources taking part in the energy and reserve markets using the Aumann-Shapley method was discussed in [17]. In [18], a profit-sharing scheme based on Owen solution (dual profit division) was introduced for a group of wind parks participating in the electricity markets jointly.

\section{B. Research Gaps}

In the literature, there is a direct deficiency or insufficient information on the following issues:

1) A limited body of research has put the focus on the trading problem of the BPPs. In [9] and [14], as few works on this topic, all BPP's cost sources (biofuel as well as operation and maintenance cost) have been overlooked, implying that those models could not represent the BPP's actual trading model. Moreover, both shortterm and long-term operation analyses of such renewable resources demand proper modeling of all impactful cost sources, which the current literature has failed to fill this research gap.

2) The existing research $[4]-[18]$ has neglected to provide a cooperative trading model for a BPP along with a concentrating solar facility and a wind park. It is utterly unknown to each of the mentioned resources what the added value of such cooperative trading is. Further, the lucrativeness of such a coalitional trading model has not been judged yet.

3) The majority of existing studies [4]-[14] have not put forward profit allocation mechanisms in their trading models, while those who succeed in doing so [15][18] did not focus on presenting a comparative study 
This article has been accepted for publication in a future issue of this journal, but has not been fully edited. Content may change prior to final publication. Citation information: DOI10.1109/TSTE.2021.3138777, IEEE Transactions on Sustainable Energy

TABLE I: Benefits of the proposed model over the frameworks given in the related literature.

\begin{tabular}{|c|c|c|c|c|c|c|c|c|c|}
\hline \multirow{2}{*}{ Ref. } & \multirow{2}{*}{ System } & \multicolumn{3}{|c|}{ Involved Markets } & \multirow{2}{*}{ Cost Sources } & \multirow{2}{*}{ Profit Allocation Method } & \multicolumn{3}{|c|}{ Cost-Benefit Analysis } \\
\hline & & DA & AD & BAL & & & $\mathbf{P B P}$ & IRR & NPV \\
\hline 14 & Wind & $\checkmark$ & - & $\checkmark$ & - & - & - & - & - \\
\hline$[\overline{5}]$ & Wind & $\checkmark$ & - & $\checkmark$ & - & - & - & - & - \\
\hline $\mid \overline{\overline{6}}$ & Wind+DR & $\checkmark$ & - & - & - & - & - & - & - \\
\hline$|7|$ & CSP & $\checkmark$ & - & $\checkmark$ & Operation cost of CSP & - & - & - & - \\
\hline$[8]$ & CSP & $\checkmark$ & - & - & - & - & - & - & - \\
\hline$[\overline{9}]$ & Solar+BPP & $\checkmark$ & - & $\checkmark$ & - & - & - & - & - \\
\hline$[10]$ & CHP & $\checkmark$ & - & - & Operation cost of CHP & - & - & - & - \\
\hline$[11$ & $\mathrm{CSP}+\mathrm{Wind}$ & $\checkmark$ & - & $\checkmark$ & - & - & - & - & - \\
\hline$[12]$ & CSP+Wind+CAES+DR & $\checkmark$ & $\checkmark$ & $\checkmark$ & O\&M cost of CAES & - & - & - & - \\
\hline$[13$ & Wind+ESS+DR & $\checkmark$ & $\checkmark$ & $\checkmark$ & - & - & - & - & - \\
\hline$[14$ & $\mathrm{BPP}+\mathrm{CSP}$ & $\checkmark$ & $\checkmark$ & - & Biofuel & - & - & - & - \\
\hline 15 & Wind+P2G & $\checkmark$ & - & $\checkmark$ & - & Nucleolus+Shapley & $\checkmark$ & - & - \\
\hline 116 & CSP+Wind & $\checkmark$ & - & $\checkmark$ & - & Nash bargaining & - & - & - \\
\hline 17 & DSR & $\checkmark$ & - & - & - & Aumann-Shapley & - & - & - \\
\hline$[18]$ & Wind & $\checkmark$ & $\checkmark$ & $\checkmark$ & - & Owen solution & - & - & - \\
\hline This work & $\mathrm{CSP}+\mathrm{BPP}+$ Wind & $\checkmark$ & $\checkmark$ & $\checkmark$ & Biofuel+ O\&M cost of all resources & $\tau$-value+Nucleolus+Shapley & $\checkmark$ & $\checkmark$ & $\checkmark$ \\
\hline
\end{tabular}

Acronyms: AD-Adjustment; BAL-Balancing; BPP-Biomass Power Plant; CAES-Compressed Air Energy Storage; CHP-Combined Heat and Power; CSP-Concentrating Solar Power; DA-Day-Ahead; DR-Demand Response; DSR-Demand Side Resources; ESS-Energy Storage System; IRR-Internal Rate of Return; NPV-Net Present Value; O\&M-Operation \& Maintenance; PBP-Payback Period

on the well-documented profit allocation methods. Besides, drawing a conclusion on the performance of those well-documented profit allocation methods in electricity market trading problems is a research gap.

4) Focusing on the ever-increasing role of BPPs worldwide, the existing works have done no study on the investment feasibility of BPPs concerning cooperative and noncooperative trading models. With this, the impact of several underlying factors on the cost-benefit analysis of BPPs is a knowledge gap.

\section{Paper's Contributions and Organization}

Motivated by the points mentioned in $\mathrm{I}-\mathrm{B}$, this paper proposes a novel coalitional trading model for a BPP, concentrating solar power facility, and a wind park in day-ahead and adjustment markets wherein the physical coupling between biomass and concentrating solar power facilities is established to enhance the overall system's flexibility. The proposed coalitional trading is built on a three-stage stochastic setting to enter the contained uncertainties, i.e., market and source-generation uncertainties. Furthermore, all cost sources associated with the operation and maintenance of included resources (wind park, biomass, and concentrating solar facilities) and biofuel are accounted to accurately construct the intended trading model. The surplus profit to each member of the proposed coalitional trading framework is designated by $\tau$-value, nucleolus, and Shapley-value techniques. At last, a cost-benefit analysis focusing on payback period, Internal Rate of Return (IRR), and Net Present Value (NPV) from the viewpoint of the BPP is performed in light of rapidly evolving biomass generation across the world. The benefits of the proposed model over the frameworks given in the related literature [4]-[18] are exhibited in Table I] The unique contributions of this work to bridge the scientific gaps mentioned above are:
- Coalitional trading: An innovative coalitional trading model for a BPP, a concentrated solar power facility, and a wind park in day-ahead and adjustment markets is presented. The literature survey reveals this work is the first to propose such a coalitional trading model. Therefore, for the first time in the literature, the added value of such a coalitional trading model from the viewpoint of all existing resources is explored.

- Cost modeling: The cost incurred by operation and maintenance of all contained resources and biofuel, including harvesting and transportation of forestry residue, are modeled in the proposed scheduling model. Conventional models for trading in the electricity markets are flawed in incorporating all these cost sources and thus presenting a real-life trading model which is practical for both shortterm and long-term operation analyses.

- Profit allocation: The profit allocation to each member of the suggested coalitional member is derived using $\tau$ value, nucleolus, and Shapley-value. This paper presents a comparative study between these well-documented profitsharing mechanisms and therefore draws a practical conclusion in electricity market trading problems to fill the existing research gap, as stated above.

- Cost-benefit analysis: Concentrating on the BPP, a costbenefit analysis is carried out to analyze the impact of several underlying factors on the BPP's investment feasibility. The cost-benefit analysis performed in this paper is the first in the literature, which takes into account the payback period, IRR, and NPV.

The paper's remainder is organized as follows. Problem description and formulation are presented in Sections II and III respectively. Game-based profit allocation methods and case studies are given in Sections IV and V, respectively. At last, Section VI presents the conclusions. 
This article has been accepted for publication in a future issue of this journal, but has not been fully edited. Content may change prior to final publication. Citation information: DOI10.1109/TSTE.2021.3138777, IEEE Transactions on Sustainable Energy

\section{PROBLEM DESCRIPTION}

\section{A. Market Model}

This paper considers the optimal trading of the intended coalition in the pool electricity market, which possesses different trading venues, including day-ahead, adjustment, and realtime balancing markets [19]. Motivated by the Spanish market, the coalition takes part in day-ahead and adjustment trading venues while covering its alteration from the settled schedule in the real-time balancing market [20]. In order to take part in the day-ahead market of day $J$, the coalition must submit its energy selling pack to the pool at 10 o'clock in the morning of day $J-1$ [20]. After the day-ahead market closure, the results of this market are proclaimed. Next, the coalition participates in the adjustment market, a trading venue that aids the supply sources in adjusting their scheduling before the delivery time in day $J$. The adjustment market closure is one hour before midnight of day $J-1$ [20]. After the adjustment market closure, the results of this market are announced. Finally, the last trading venue is the real-time balancing market, which takes place in day $J$, dealing with the deviations caused by the non-dispatchable member of the coalition, i.e., wind park [20]. Given the real-time balancing market, the coalition encounters two operating situations: short or long. If there is a generation deficit between the settled schedule and the delivered energy in the real-time operation, the coalition operates short; otherwise, the long operating situation occurs. In the short situation, the coalition needs to purchase the deficit energy at a price higher than or equal to the day-ahead price. By contrast, the coalition's excess energy in the long situation is purchased at a price lower than or equal to the day-ahead price [20]. To sum up, the coalition's optimal involvement in the discussed trading venues follows three sequential stages, as displayed in Fig. 1 .

\section{B. Model Assumptions}

For clarification, the paramount model assumptions are itemized below:

1) In this paper, a forestry BPP in accordance with several BPPs operating in the Spanish electricity market is considered. The forestry residue required for the BPP is gathered by the forestry gathering and management unit within 100 kilometers around the plant [21]. Note that all wood residues are collected from forests certified by Forest Stewardship Council. Accordingly, harvesting and transportation costs of forestry residue constitute the biofuel cost. Furthermore, since biofuel's annual capacity is finite, the BPP devotes a specified capacity of forestry residue for daily operation [9], [22].

2) In order to address uncertain factors as well as capturing the discussed market model, a three-stage stochastic approach is leveraged. All uncertain factors are described by simulated scenarios applying normal distribution [8], [12], [15], [23]:

$$
f(x)=\frac{1}{\sigma \sqrt{2 \pi}} e^{-\frac{1}{2}\left(\frac{x-\mu}{\sigma}\right)^{2}}
$$

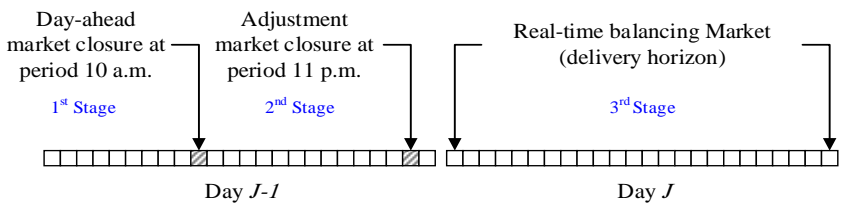

Fig. 1: The considered market model.

where $x$ is the uncertain parameter, while $\sigma$ and $\mu$ stand for the standard deviation and mean of the distribution, respectively. By fitting normal distribution to historical data of the intended parameter, the desired number of scenarios for the uncertain parameter can be generated.

3) The coalition's trading in the considered market model does not influence market's results, implying that the coalition is price-taker [20].

\section{Proposed Coalitional Trading Formulation}

In this section, a mathematical representation for the intended coalitional trading model to maximize the coalition's overall profit is presented. The schematic of the suggested coalition is given in Fig. 3 . As can be seen, a single BiomassConcentrating Solar (BCS) powerblock is embedded to convert thermal energy jointly received from the biomass-fired boiler, thermal energy storage, and solar field. The thermal energy storage is placed between the biomass-fired boiler and solar field to store energy from these units. The coalition manages the output electric powers from the BCS powerblock and wind park to optimize its involvement in the considered trading venues constructively. Benefiting from the three-stage stochastic setting, the objective function of the coalitional trading model is formulated as follows:

$$
\operatorname{Max} \sum_{\omega \in \Omega} \pi_{\omega} \sum_{t \in \mathcal{T}}\left(\varepsilon_{t, \omega}^{1}+\varepsilon_{t, \omega}^{2}+\varepsilon_{t, \omega}^{3}\right)
$$

where $\varepsilon_{t, \omega}^{1}, \varepsilon_{t, \omega}^{2}$, and $\varepsilon_{t, \omega}^{3}$ denote the coalitions' earning from $1^{\text {st }}, 2^{\text {nd }}, 3^{r d}$ stages of the designed three-stage stochastic setting, i.e., day-ahead, adjustment, and real-time balancing markets, respectively. Three-stage stochastic setting holds the following sequence of decisions [24]:

1) $1^{\text {st }}$ stage decisions: Before the realization of the dayahead prices (before 10 a.m. of day $J-1$ in Fig. 1), the coalition decides on its energy selling pack to the dayahead market and the commitment status of the biomassfired boiler, powerblock, and thermal energy storage.

2) $2^{\text {nd }}$ stage decisions: After proclaiming the day-ahead market results (before 11 p.m. of day $J-1$ in Fig. 1), the coalition determines its involvement in the adjustment market. At this stage, adjustment prices and sourcegeneration (solar field and wind park) powers are still unknown to the coalition.

3) $3^{\text {rd }}$ stage decision: After all uncertain parameters became known to the coalition in the real-time balancing market (delivery horizon in Fig. 1), the deviation of the coalition from its settled schedule when it is operating long/short is determined.

The coalition's earning in the $1^{\text {st }}$ trading venue (day-ahead market) is expressed by (3), wherein the first and second terms 


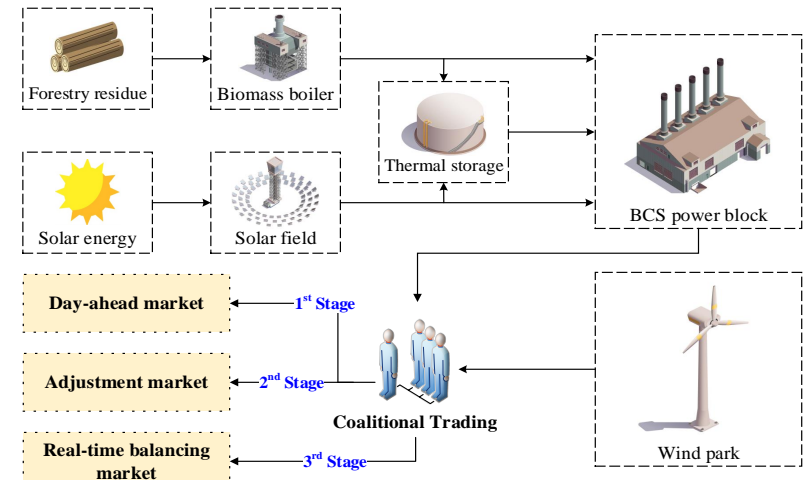

Fig. 2: Schematic of the proposed coalitional trading model.

are respectively associated with the earnings of the wind park and the BCS unit.

$$
\varepsilon_{t, \omega}^{1}=\lambda_{t, \omega}^{\mathrm{D}} p_{t, \omega}^{\mathrm{D}, \mathrm{W}}+\lambda_{t, \omega}^{\mathrm{D}} p_{t, \omega}^{\mathrm{D}, \mathrm{BC}} ; \quad \forall t \in \mathcal{T}, \forall \omega \in \Omega
$$

The coalitions' transactions in the $2^{\text {nd }}$ trading venue (adjustment market) are modeled by (4). In (4), the first term shows the coalition's income by presenting an energy selling pack, whereas the second term represents the coalition's expense by presenting an energy purchasing pack to the $2^{\text {nd }}$ trading venue. It is worth noting that all kinds of supply sources mostly just present energy selling packs to the day-ahead market. By contrast, supply sources having intermittent power plants offer both energy selling and purchasing packs to the adjustment market to adjust to forecast errors [20]. The last two terms in (4) are costs of BPP and concentrating solar facility, respectively. The BPP's cost arises from harvesting and transportation of forestry residue and its operation and maintenance, as expressed in (5). The cost of concentrating solar facility originates from its operation and maintenance, as defined in (6).

$$
\begin{array}{r}
\varepsilon_{t, \omega}^{2}=\lambda_{t, \omega}^{\mathrm{A}}\left(p_{t, \omega}^{\mathrm{A}, \mathrm{BC}}+p_{t, \omega}^{\mathrm{A}, \mathrm{W}^{\prime}}\right)-\lambda_{t, \omega}^{\mathrm{A}} p_{t, \omega}^{\mathrm{A}, \mathrm{W}^{\prime \prime}}-\Phi_{t, \omega}^{\mathrm{BP}}-\Phi_{t, \omega}^{\mathrm{CS}} ; \\
\forall t \in \mathcal{T}, \forall \omega \in \Omega \\
\Phi_{t, \omega}^{\mathrm{BP}}=b_{t, \omega} c^{\mathrm{H}}+b_{t, \omega} c^{\mathrm{Tr}}+\left(q^{\mathrm{y}, \mathrm{b}}+q^{\mathrm{x}, \mathrm{b}}\right) \eta_{1} c^{\mathrm{BP}} \\
\forall t \in \mathcal{T}, \forall \omega \in \Omega \\
\Phi_{t, \omega}^{\mathrm{CS}}=\left(q^{\mathrm{y}, \mathrm{f}}+q^{\mathrm{x}, \mathrm{f}}\right) \eta_{1} c^{\mathrm{CS}} ; \quad \forall t \in \mathcal{T}, \forall \omega \in \Omega
\end{array}
$$

The coalitions' earning in the $3^{\text {rd }}$ trading venue (real-time balancing market) is described by (7). In (7), the first two terms show the coalition's income and expense in long and short operating situations, respectively. The last term in this equation models the operation and maintenance cost of the wind park.

$\varepsilon_{t, \omega}^{3}=\lambda_{t, \omega}^{\mathrm{D}} o_{t, \omega}^{+} \epsilon_{t, \omega}^{+}-\lambda_{t, \omega}^{\mathrm{D}} o_{t, \omega}^{-} \epsilon_{t, \omega}^{-}-G_{t, \omega}^{\mathrm{W}} c^{\mathrm{W}} ; \forall t \in \mathcal{T}, \forall \omega \in \Omega$

The techno-economic constraints of the proposed coalitional trading are described in the following subsections.

\section{A. Biomass-Fired Boiler Constraints}

The generated power of the biomass-fired boiler, which is a function of forestry residue burnt in the boiler, is computed by $(8)$. The amount of forestry residue fed into the biomassfired boiler is finite and limited by the available daily capacity, as modeled in (9). The biomass-fired boiler needs to work in the rated operational range, hence, the lower and upper bounds of biomass-fired boiler's generated power are enforced in (10), whereas Equation (11) ensures that it is equal to the power conveyed to the thermal energy storage and the BCS powerblock. Indeed, (11) is the thermal energy balance of the biomass-fired boiler. The portion of electric power produced by the biomass-fired boiler as a result of transferring thermal energy to the BCS powerblock is quantified in (12).

$$
\begin{gathered}
q_{t, \omega}^{\mathrm{b}}=\eta_{2} \chi k_{t, \omega} ; \quad \forall t \in \mathcal{T}, \forall \omega \in \Omega \\
0 \leq \sum_{t \in \mathcal{T}} k_{t, \omega}^{\mathrm{b}}-K \leq 0 ; \quad \forall \omega \in \Omega \\
\frac{Q^{\mathrm{b}} \alpha_{t}^{\mathrm{b}} \leq q_{t, \omega}^{\mathrm{b}} \leq \overline{Q^{\mathrm{b}}} \alpha_{t}^{\mathrm{b}} ; \quad \forall t \in \mathcal{T}, \forall \omega \in \Omega}{q_{t, \omega}^{\mathrm{b}}=q_{t, \omega}^{\mathrm{y}, \mathrm{b}}+q_{t, \omega}^{\mathrm{x}, \mathrm{b}} ; \quad \forall t \in \mathcal{T}, \forall \omega \in \Omega} \\
p_{t, \omega}^{\mathrm{y}, \mathrm{b}}=\eta_{1} q_{t, \omega}^{\mathrm{y}, \mathrm{b}} ; \quad \forall t \in \mathcal{T}, \forall \omega \in \Omega
\end{gathered}
$$

\section{B. Solar Field Constraints}

The portion of electric power produced by the solar field on account of transferring thermal energy to the BCS powerblock is calculated in (13). Note that the output thermal energy of the solar field is transferred to the BCS powerblock or the thermal energy storage. Constraint (14) guarantees that the solar field's thermal energy is conveyed to the thermal energy storage or the BCS powerblock, while the overall conveyed thermal energy should be lower than the output thermal power of the solar field.

$$
\begin{gathered}
p_{t, \omega}^{\mathrm{y}, \mathrm{f}}=\eta_{1} q_{t, \omega}^{\mathrm{y}, \mathrm{f}} ; \quad \forall t \in \mathcal{T}, \forall \omega \in \Omega \\
0 \leq q_{t, \omega}^{\mathrm{y}, \mathrm{f}}+q_{t, \omega}^{\mathrm{x}, \mathrm{f}} \leq G_{t, \omega}^{\mathrm{F}} ; \quad \forall t \in \mathcal{T}, \forall \omega \in \Omega
\end{gathered}
$$

\section{Thermal Energy Storage Constraints}

The portion of electric power produced by the thermal energy storage resulting from conveying thermal energy to the BCS powerblock is computed in (15). The charge and discharge processes of the thermal energy storage have to be consistent with its rated operational range, thus, the upper bounds of discharge and charge in the thermal energy storage are enforced by (16) and (17), respectively. Constraint (18) prohibits the thermal energy storage from being run in discharge and charge modes simultaneously. In other words, the thermal energy storage can only be operated in discharge or charge modes at each period. Thermal energy storage is only allowed to convey energy to the BCS powerblock when the powerblock is online, as expressed in (19). It has to be noted that conveying energy from thermal energy storage to an offline BCS powerblock is impractical. The state of charge of the thermal energy storage at $t=1$ and the rest of the trading 
This article has been accepted for publication in a future issue of this journal, but has not been fully edited. Content may change prior to final publication. Citation information: DOI10.1109/TSTE.2021.3138777, IEEE Transactions on Sustainable Energy

periods are modeled by (20) and (21), respectively. These two constraints show the available energy at the thermal energy storage at any period. Constraint 22] reflects that the initial state of charge of the thermal energy storage should be equal to its state of charge at the last trading period. This constraint prevents trading problems from being affected by the initial state of charge in the coming scheduling horizons (days). Constraint (23) bounds the state of charge of the thermal energy storage inside its upper and lower boundaries to be run within its rated operational range.

$$
\begin{gathered}
p_{t, \omega}^{\mathrm{z}}=\eta_{1} q_{t, \omega}^{\mathrm{z}} ; \quad \forall t \in \mathcal{T}, \forall \omega \in \Omega \\
q_{t, \omega}^{\mathrm{z}} \leq \overline{\varsigma^{\mathrm{dis}}} \gamma_{t}^{\mathrm{dis}} ; \quad \forall t \in \mathcal{T}, \forall \omega \in \Omega \\
q_{t, \omega}^{\mathrm{x}, \mathrm{b}} \leq \overline{\varsigma^{\mathrm{ch}}} \gamma_{t}^{\mathrm{ch}}, q_{t, \omega}^{\mathrm{x}, \mathrm{f}} \leq \overline{\varsigma^{\mathrm{ch}}} \gamma_{t}^{\mathrm{ch}} ; \quad \forall t \in \mathcal{T}, \forall \omega \in \Omega \\
\gamma_{t}^{\mathrm{ch}}+\gamma_{t}^{\mathrm{dis}}-1 \leq 0 ; \quad \forall t \in \mathcal{T} \\
\alpha_{t}^{\mathrm{pb}}-\gamma_{t}^{\mathrm{dis}} \leq 0 ; \quad \forall t \in \mathcal{T} \\
q_{t, \omega}^{\Xi}=q_{0}^{\Xi}+q_{t, \omega}^{\mathrm{x}, \mathrm{b}}+q_{t, \omega}^{\mathrm{x}, \mathrm{f}}-q_{t, s i}^{\mathrm{z}} ; \quad \forall t=1, \forall \omega \in \Omega \\
q_{t, \omega}^{\Xi}=q_{t-1, \omega}^{\Xi}+q_{t, \omega}^{\mathrm{x}, \mathrm{b}}+q_{t, \omega}^{\mathrm{x}, \mathrm{f}}-q_{t, \omega}^{\mathrm{z}} ; \quad \forall t \geq 2, \forall \omega \in \Omega \\
q_{t=24, \omega}^{\Xi}=q_{0}^{\Xi} ; \quad \forall t=24, \forall \omega \in \Omega \\
Q^{\Xi} \leq q_{t, \omega}^{\Xi} \leq \overline{Q^{\Xi}} ; \quad \forall t \in \mathcal{T}, \forall \omega \in \Omega
\end{gathered}
$$

\section{BCS Powerblock Constraints}

The power of the BCS powerblock is computed by 24. Actually, this equation describes the power balance of the BCS powerblock. The BCS powerblock's output power should not exceed designated operating limits (upper and lower bounds), as defined in 25. Thermal power input to the BCS powerblock, which is a function of its output electric power and the thermal power needed to power-up the powerblock, is defined in (26), while power-up status of the BCS powerblock is imposed in (27). Constraint (28) reflects the lower and upper bounds of the thermal power input to the BCS powerblock. In fact, this constraint enforces the rated operating range of the input thermal power of the BCS powerblock. Ramping-up and ramping-down limits of the BCS powerblock are represented by (29) and (30), respectively. These constraints prevent the BCS powerblock from impractical ramping operations.

$$
\begin{gathered}
p_{t, \omega}^{\mathrm{pb}}=p_{t, \omega}^{\mathrm{D}, \mathrm{BC}}+p_{t, \omega}^{\mathrm{A}, \mathrm{BC}}=p_{t, \omega}^{\mathrm{y}, \mathrm{b}}+p_{t, \omega}^{\mathrm{y}, \mathrm{f}}+p_{t, \omega}^{\mathrm{z}} ; \forall t \in \mathcal{T}, \forall \omega \in \Omega \\
0 \leq p_{t, \omega}^{\mathrm{pb}} \leq \overline{P^{\mathrm{pb}}} ; \quad \forall t \in \mathcal{T}, \forall \omega \in \Omega \\
q_{t, \omega}^{\mathrm{pb}}-q^{\mathrm{STU}} \beta_{t}=\frac{p_{t, \omega}^{\mathrm{pb}}}{\eta_{1}} ; \quad \forall t \in \mathcal{T}, \forall \omega \in \Omega \\
\beta_{t}=\alpha_{t}^{\mathrm{pb}}-\alpha_{t-1}^{\mathrm{pb}} ; \quad \forall t \in \mathcal{T} \\
\underline{Q^{\mathrm{pb}}} \alpha_{t}^{\mathrm{pb}} \leq q_{t, \omega}^{\mathrm{pb}} \leq \overline{Q^{\mathrm{pb}}} \alpha_{t}^{\mathrm{pb}} ; \quad \forall t \in \mathcal{T}, \forall \omega \in \Omega \\
p_{t, \omega}^{\mathrm{pb}}-p_{t-1, \omega}^{\mathrm{pb}} \leq \varpi^{\mathrm{up}} ; \quad \forall t \in \mathcal{T}, \forall \omega \in \Omega \\
p_{t-1, \omega}^{\mathrm{pb}}-p_{t, \omega}^{\mathrm{pb}} \leq \varpi^{\mathrm{down}} ; \quad \forall t \in \mathcal{T}, \forall \omega \in \Omega
\end{gathered}
$$

\section{E. Coalitional Trading Constraints}

The power sold to or purchased from the adjustment market by the coalition is restricted by [31] [12]. Note that coalition's trading in the adjustment market should be limited to prevent influencing adjustment market results for a price-taker producer [25]. The coalition's deviation from its settled schedule in the real-time balancing market while operating long or short are modeled in (32)-(36). Equation (32) calculates the overall coalition's deviation from its settled schedule in the real-time balancing market. The arranged electric power of the coalition, which is the sum of the power sold to dayahead and adjustment trading venues minus power purchased from the same venues, is quantified in (33). The coalition's deviation when it is operating short cannot be greater than its maximum in-hand capacity, while the coalition's deviation when it is operating long cannot be greater than its operating power, as defined in (34) and (35), respectively. Constraint (35) limits the arranged electric power of the coalition within its maximum in-hand capacity. The ascending constraint of energy selling packs to the day-ahead trading venue is imposed by (37)-38] [12]. At last, limitations 396-(41) guarantee the nonanticipativity of transactions in day-ahead and adjustment trading venues [12].

$$
\begin{gathered}
0 \leq \Upsilon \leq \Delta\left(\overline{P^{\mathrm{pb}}}+\overline{P^{\mathrm{W}}}\right) ; \quad \forall t \in \mathcal{T}, \forall \omega \in \Omega \\
\Upsilon=\left[p_{t, \omega}^{\mathrm{A}, \mathrm{W}^{\prime \prime}},\left(p_{t, \omega}^{\mathrm{A}, \mathrm{W}^{\prime}}+p_{t, \omega}^{\mathrm{A}, \mathrm{BC}}\right)\right] \\
\epsilon_{t, \omega}^{-}-\epsilon_{t, \omega}^{+}=p_{t, \omega}^{\mathrm{Sch}}-p_{t, \omega}^{\mathrm{pb}}-G_{t, \omega}^{\mathrm{W}} ; \quad \forall t \in \mathcal{T}, \forall \omega \in \Omega \\
p_{t, \omega}^{\mathrm{Sch}}=p_{t, \omega}^{\mathrm{D}, \mathrm{W}}+p_{t, \omega}^{\mathrm{pb}}+p_{t, \omega}^{\mathrm{A}, \mathrm{W}^{\prime}}-p_{t, \omega}^{\mathrm{A}, \mathrm{W}^{\prime \prime}} ; \forall t \in \mathcal{T}, \forall \omega \in \Omega \\
0 \leq \epsilon_{t, \omega}^{-} \leq \overline{P^{\mathrm{pb}}} \alpha_{t}^{p b}+\overline{P^{\mathrm{W}}} ; \quad \forall t \in \mathcal{T}, \forall \omega \in \Omega \\
0 \leq \epsilon_{t, \omega}^{+} \leq p_{t, \omega}^{\mathrm{pb}}+G_{t, \omega}^{\mathrm{W}} ; \quad \forall t \in \mathcal{T}, \forall \omega \in \Omega \\
0 \leq p_{t, \omega}^{\mathrm{Sch}} \leq \overline{P^{\mathrm{pb}}} \alpha_{t}^{p b}+\overline{P^{\mathrm{W}}} ; \quad \forall t \in \mathcal{T}, \forall \omega \in \Omega \\
p_{t, \omega}^{\mathrm{D}, \mathrm{BC}} \geq p_{t, \breve{\omega}}^{\mathrm{D}, \mathrm{BC}} \text { if } \lambda_{t, \omega}^{\mathrm{D}}-\lambda_{t, \breve{\omega}}^{\mathrm{D}} \geq 0 ; \forall t \in \mathcal{T}, \forall \omega, \breve{\omega} \in \Omega \\
p_{t, \omega}^{\mathrm{D}, \mathrm{W}} \geq p_{t, \breve{\omega}}^{\mathrm{D}, \mathrm{W}} \text { if } \lambda_{t, \omega}^{\mathrm{D}}-\lambda_{t, \breve{\omega}}^{\mathrm{D}} \geq 0 ; \forall t \in \mathcal{T}, \forall \omega, \breve{\omega} \in \Omega \\
p_{t, \omega}^{\mathrm{D}, \mathrm{BC}}=p_{t, \breve{\omega}}^{\mathrm{D}, \mathrm{BC}} \text { if } \lambda_{t, \omega}^{\mathrm{D}}-\lambda_{t, \breve{\omega}}^{\mathrm{D}}=0 ; \forall t \in \mathcal{T}, \forall \omega, \breve{\omega} \in \Omega \\
p_{t, \omega}^{\mathrm{D}, \mathrm{W}}=p_{t, \breve{\omega}}^{\mathrm{D}, \mathrm{W}} \text { if } \lambda_{t, \omega}^{\mathrm{D}}-\lambda_{t, \breve{\omega}}^{\mathrm{D}}=0 ; \forall t \in \mathcal{T}, \forall \omega, \breve{\omega} \in \Omega \\
p_{t, \omega}^{\mathrm{A}, \xi}=p_{t, \breve{\omega}}^{\mathrm{A}, \xi} \text { if } \lambda_{t, \omega}^{\mathrm{D}}-\lambda_{t, \breve{\omega}}^{\mathrm{D}}=0 ; \quad \forall t \in \mathcal{T}, \forall \omega, \breve{\omega} \in \Omega
\end{gathered}
$$

\section{Profit Allocation Methods}

In trading problems managed by a coalition, the underlying concern is how much profit has to be allocated to each coalition member. This gives birth to the idea of cooperative game models. In this work, $\tau$-value, nucleolus, and Shapleyvalue are exploited and compared for fair profit sharing to the coalition members, i.e., BPP, concentrating solar power facility, and wind park, as three principal classes of cooperative games. It is worth noting that these methods have not been jointly considered before for trading problems; nevertheless, 
these are different approaches to distribute profit among coalition members. They will thus be introduced in this section and compared in the case study.

\section{A. $\tau$-Value Theorem}

The concept of $\tau$-value was first proposed by Tijs in 1981 [26]. The main characteristic of this theorem is that the core of the $\tau$-value is non-empty for balanced games. The $\tau$-value is founded on the utopia point $\mathcal{M}(v)$ and minimum right vector $\mathcal{R}(v)$ of a specific game with characteristic function $v$. Based on this method, the profit allocated to each member $i$ of coalition $\left(u_{i}(v)\right)$, namely, BPP, concentrating solar power facility, and wind park, is obtained using the following equation.

$$
u_{i}(v)=\mathcal{R}_{i}(v)+\varkappa\left[\mathcal{M}_{i}(v)-\mathcal{R}_{i}(v)\right]
$$

where if $\mathcal{M}_{i}(v)=\mathcal{R}_{i}(v)$, then $\varkappa=0$, if not:

$$
\varkappa=\left(\sum_{i=1}^{n} \mathcal{M}_{i}(v)-\sum_{i=1}^{n} \mathcal{R}_{i}(v)\right)^{-1}\left(v(\mathcal{I})-\sum_{i=1}^{n} \mathcal{R}_{i}(v)\right)
$$

where $v(\mathcal{I})$ refers to the profit gained by the proposed coalitional trading model, i.e., grand coalition $\mathcal{I}$, where all coalition members participate in the trading problem, and $n$ is the total number of coalition members. Note that $\mathcal{M}_{i}(v)$ and $\mathcal{R}_{i}(v)$ in the preceding equations are obtained employing (44) and (45), respectively.

$$
\begin{gathered}
\mathcal{M}_{i}(v)=v(\mathcal{I})-v(\mathcal{I}-\{i\}) \\
\mathcal{R}_{i}(v)=\operatorname{Max} \mathcal{R M}_{i}(\mathcal{S})=\operatorname{Max}\left(v(\mathcal{S})-\sum_{\iota \in \mathcal{S}-\{i\}} \mathcal{M}_{\iota}(v)\right)
\end{gathered}
$$

where $\mathcal{R M}_{i}(\mathcal{S})$ is known as the remainder of coalition member $i$ in coalition $\mathcal{S}[26]$, and $v(\mathcal{S})$ denotes the profit gained while members in $\mathcal{S}$ cooperate in the trading.

\section{B. Nucleolus Theorem}

In 1969, Schmeidler introduced the nucleolus theorem [27]. Based on this theorem, the nucleolus is obtained at a point where the dissatisfaction of all coalition members is minimized. This theorem's principal feature is that the nucleolus is invariably an element of the core for balanced games. To obtain the profit allocated to each coalition member, the following linear optimization problem should be solved [28]:

$$
\begin{gathered}
\operatorname{Min} \zeta \\
\text { s.t. } V(\mathcal{S})=\sum_{i \in \mathcal{S}_{1}} y_{i} \\
V(\mathcal{S})-\sum_{i \in \mathcal{S}_{2}} y_{i} \leq \zeta
\end{gathered}
$$

where $V(\mathcal{S})$ represents the profit built via the alternation of the coalition members and $y_{i}$ refers to profit allocation imputation to coalition member $i$. Further, in (47) and (48, $\mathcal{S}_{1}$ refers to the grand coalition $(\mathcal{I})$, and $\mathcal{S}_{2}$ constitutes all non-empty subcoalitions of coalition members, i.e., BPP, concentrating solar power facility, and wind park. Note that $V(\mathcal{S})$ is defined based on the following equation.

$$
V(\mathcal{S})=v(\mathcal{S})-\sum_{i \in \mathcal{S}} \vartheta(i)
$$

Eventually, by having the profit gained through the individual (non-cooperative) trading models $\vartheta(i)$, the assigned profit to the coalition members $u(i)$ is computed using (50).

$$
u_{i}(v)=\vartheta(i)+y_{i}
$$

\section{Shapley-value Theorem}

The theorem of Shapley-value for cooperative games was founded by Shapley in 1953 [29]. The apportioned profit to the coalition members founded on the Shapley-Value $u(i)$ is computed by:

$$
u_{i}(v)=\sum_{\mathcal{S}: i \notin \mathcal{S}} \frac{(n-|\mathcal{S}|) !(|\mathcal{S}|-1) !}{n !}[v(\mathcal{S})-v(\mathcal{S}-\{i\})]
$$

where $n$ is the total number of members participating in the coalitional trading, $|\mathcal{S}|$ is the number of members in coalition $\mathcal{S}$, and $v(\mathcal{S})-v(\mathcal{S}-\{i\})$ indicates the incremental profit that can be obtained by member $i$ in coalition $\mathcal{S}$. At last, $n$ ! stands for the permutations that we can build from the members in $\mathcal{I}$, grand coalition. The in-depth descriptions of these three cooperative games are given in [26]-[29] for interested readers.

\section{CAse Study}

BPP and concentrating solar power facility with $50 \mathrm{MW}$ power capacities are coupled to build a $100 \mathrm{MW}$ BCS unit. The wind park capacity is $173.45 \mathrm{MW}$. The operation and maintenance costs of the BPP, concentrating solar power facility, and wind park are $3.18 € / \mathrm{MWh}, 0.92 € / \mathrm{MWh}$, and 16.26 $€ / M W h$, respectively. 800 Oven-Dry Tons (o.d.t) forestry residue with $4.067 \mathrm{MWh} /$ ton heating value is considered as the daily available biofuel for the BPP. The harvesting and transportation costs of forestry residue are $36.28 € /$ o.d.t and $18.37 € /$ o.d.t, respectively [30]. The ramping-up/down bound of the BCS powerblock is set to $40 \%$ of its hourly maximum generation limit. Other data corresponding to the available units are listed in Table II The coefficient related to restricting power sold to or purchased from the adjustment market $\Delta$ is set to 0.3 [12].

TABLE II: Other Parameters of the BCS powerblock, thermal energy storage, and biomass-fired boiler

\begin{tabular}{|c|c|c|c|}
\hline Parameter & Value & Parameter & Value \\
\hline$\underline{Q^{\mathrm{b}}}, \overline{Q^{\mathrm{b}}}$ & $0,150 \mathrm{MW}$ & $\eta_{1}$ & $89.5 \%$ \\
\hline$\underline{Q^{\mathrm{pb}}}, \overline{Q^{\mathrm{pb}}}$ & $50,250 \mathrm{MW}$ & $\eta_{2}$ & $40 \%$ \\
\hline$\underline{Q^{\Xi}}, \overline{Q^{\Xi}}$ & $120,1200 \mathrm{MWh}$ & $q^{\mathrm{STU}}$ & $10 \mathrm{MW}$ \\
\hline$\overline{\varsigma^{\mathrm{ch}}}, \overline{\varsigma^{\text {dis }}}$ & $150,150 \mathrm{MW}$ & $q_{0}^{\Xi}$ & $600 \mathrm{MWh}$ \\
\hline
\end{tabular}


This article has been accepted for publication in a future issue of this journal, but has not been fully edited. Content may change prior to final publication. Citation information: DOI10.1109/TSTE.2021.3138777, IEEE Transactions on Sustainable Energy

The developed trading problem holds a mixed-integer programming nature, which was solved by the CPLEX optimization engine in GAMS software. To demonstrate the merits of the suggested framework, two case studies are considered:

1) Optimal trading in the next-day electricity market: We quantify the lucrativeness of the proposed cooperative trading model against the non-cooperative one for a representative day.

2) Cost-benefit analysis of the BPP: We perform a costbenefit analysis for the BPP to evaluate the influence of various factors on the BPP's payback period.

\section{A. Optimal Trading in the Next-Day Electricity Market}

In this subsection, we appraise the lucrativeness of the coalitional trading model for a representative next-day electricity market, March 13, 2019 [31]. In order to represent market and source-generation uncertainties, a set of scenarios applying normal distribution are generated. To secure tractability [20], day-ahead price and source-generation scenarios are reduced to eight scenarios individually, whereas adjustment and realtime balancing prices are decreased to five apiece. The scenario reduction process is handled via GAMS SCENRED2 [32]. It must be noticed that correlation among market scenarios, day-ahead, adjustment, and real-time balancing prices, are taken into account [20]. Accordingly, the total number of scenarios for the three-stage stochastic objective function (2) is $8 \times 5 \times 5 \times 8=1600$.

For a coalitional trading problem with $n$ member, $2^{n}-1$ trading problems corresponding to all subcoalitions of coalition members have to be solved. Here, with $n=3$, we need to solve seven different trading problems in proportion to different combinations of coalition members, as shown in the left column of Table IIII. It is worthwhile to note that the optimization problem (2)-(41) conforms to coalition \{Wind park, BPP, Concentrating solar facility $\}$, last row of Table III By contrast, other coalitions' trading problems can be easily derived by adjusting the inputs of the optimization problem (2)-(41). To do so, the trading problem for each intended coalition is obtained in a way that the parameters and variables of the absent element(s) in the main optimization problem (2)-(41) should be set to zero. For instance, to obtain the optimization problem for the second row of Table III (i.e., wind park), we set the parameters and variables of the BPP and concentrating solar facility in (2)-(41) to zero and solve the optimization problem. It is worth mentioning that this formulation derives from the fact that all entities are pricetaker. Table III reports the profit of different coalitions in the next-day electricity market. As shown in Table III], the BPP earns the lowest profit due to biofuel's high cost. At the same time, the wind park gets the highest profit on account of its large capacity and wind availability at all hours. This table manifests that the larger the coalition's scale, the greater the obtained profit. Another noteworthy point that can be inferred is that increasing the scale of the coalition yields greater added value. For example, coalitions \{Wind park\} and $\{$ Concentrating solar facility $\}$ individually obtain $€ 7,321$ and $€ 13,769$, and accordingly, the overall profit of these
TABLE III: Profit of different coalitions.

\begin{tabular}{|c|c|}
\hline Coalition & Profit $(\boldsymbol{€})$ \\
\hline$\{$ Wind park $\}$ & 61,809 \\
\hline$\{$ BPP $\}$ & 7,321 \\
\hline$\{$ Concentrating solar facility $\}$ & 13,769 \\
\hline$\{$ Wind park, BPP $\}$ & 69,202 \\
\hline$\{$ Wind park, Concentrating solar facility & 75,808 \\
\hline$\{$ BPP, Concentrating solar facility & 24,536 \\
\hline$\{$ Wind park, BPP, Concentrating solar facility $\}$ & 86,674 \\
\hline
\end{tabular}

two coalitions would be $€ 21,090$. As Table III shows, the integration of BPP and concentrating solar facility in the form of coalition $\{$ BPP, Concentrating solar facility $\}$ earns $€ 24,536$, which is $€ 3,446$ more than the individual coalitions (i.e., $\{$ Wind park $\}$ and $\{$ Concentrating solar facility $\}$ ), revealing the benefit of the suggested coalitional trading model.

Table IV provides a comparison between the allocated profit to coalition members under cooperative and non-cooperative trading schemes. As reported in this table, the proposed cooperative trading framework yields $€ 3,775$ of surplus profit compared to the non-cooperative one, revealing the lucrativeness of the suggested trading framework. Table $[\mathrm{IV}$ also shows that the highest share of the total surplus profit has been allocated to the concentrating solar facility, followed by the BPP and wind park. The reason is that the concentrating solar facility and BPP are the most influential members of the coalition in terms of boosting the surplus profit. Among the profit allocation methods, the highest share of the allocated profit for the concentrating solar facility belongs to Shapleyvalue $(€ 1,847)$, followed by $\tau$-value $(€ 1,845)$ and nucleolus $(€ 1,838)$. On the flip side, the highest portion of the allocated profit for the BPP goes to the nucleolus $(€ 1,772)$, followed by Shapley-value $(€ 1,768)$ and $\tau$-value $(€ 1,766)$. Moreover, from Table IV] it is seen that the wind park is the least influential member of the coalition. However, by estimating an average of $€ 160$ daily surplus profit for the wind park, the average annual surplus profit compared to the non-cooperative trading is expected to be $€ 58,400$. This provides the reason for the wind park to remain in the coalition, thus highlighting the stability of combining these complementary technologies in future renewable-dominated power systems. Accordingly, as one can see, the best-suited profit allocation method from the viewpoint of each of the coalition members is different. For instance, the nucleolus is the most desirable approach for the wind park and the BPP as it yields the highest surplus profit, while the Shapley-value is the best choice for the concentrating solar facility. Nevertheless, the highest difference between the surplus profit of different allocation methods considering all coalition members is $€ 9$ (Shapley-value and nucleolus for the concentrating solar facility), which is trivial. Thus, the performance of various profit allocation methods can be roughly considered similar, and thus by ignoring minor differences, any of them can be leveraged by the coalition. This is fully in line with the nature of convex games (the proposed game in this paper is convex [33]). However, as remarkably discussed in the related context, it is arduous to draw a generic conclusion about profit allocation methods as numerous parameters are involved. 
This article has been accepted for publication in a future issue of this joumal, but has not been fully edited. Content may change prior to final publication. Citation information: DOI 10.1109/TSTE.2021.3138777, IEEE Transactions on Sustainable Energy

TABLE IV: Comparison between the allocated profit under cooperative and non-cooperative trading models.

\begin{tabular}{|c|c|c|c|c|c|c|c|}
\hline \multirow{3}{*}{ Coalition Member } & \multirow{3}{*}{$\begin{array}{c}\text { Non-cooperative } \\
\text { Profit (€) }\end{array}$} & \multicolumn{6}{|c|}{ Cooperative Profit ( $€$ ) } \\
\hline & & \multicolumn{2}{|c|}{$\tau$-Value } & \multicolumn{2}{|c|}{ Nucleolus } & \multicolumn{2}{|c|}{ Shapley-Value } \\
\hline & & Profit & Surplus Profit & Profit & Surplus Profit & Profit & Surplus Profit \\
\hline Wind park & 61,809 & 61,973 & 164 & 61,974 & 165 & 61,969 & 160 \\
\hline BPP & 7,321 & 9,087 & 1,766 & 9,093 & 1,772 & 9,089 & 1,768 \\
\hline Concentrating solar facility & 13,769 & 15,614 & 1,845 & 15,607 & 1,838 & 15,616 & 1,847 \\
\hline Total & 82,899 & 86674 & 3,775 & 86674 & 3,775 & 86674 & 3,775 \\
\hline
\end{tabular}
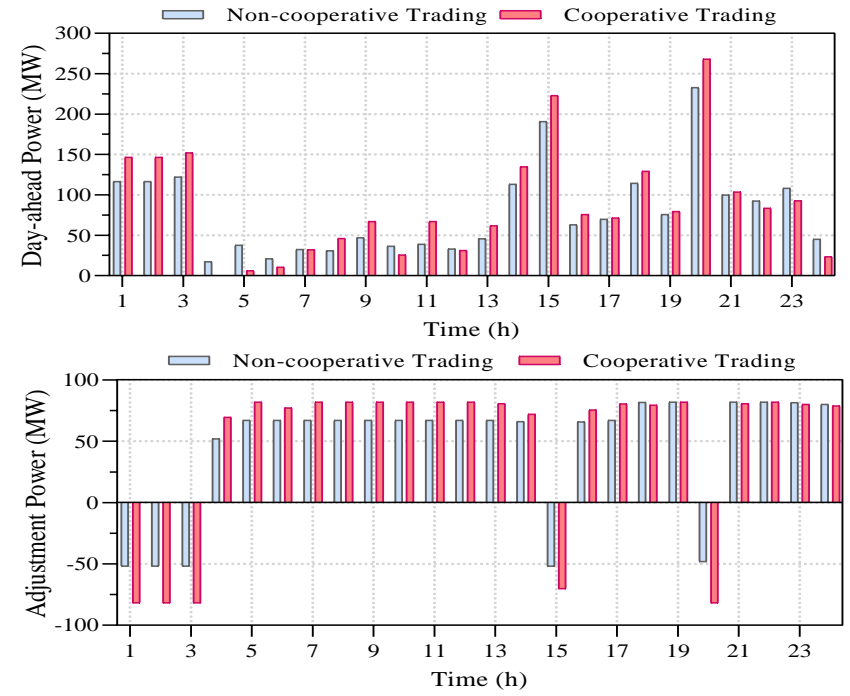

Fig. 3: Traded Power in day-ahead and adjustment markets under cooperative and non-cooperative trading models.

Fig. 4 depicts the traded power in the day-ahead and adjustment markets under cooperative and non-cooperative trading frameworks. It can be seen that by leveraging the cooperative framework, the amount of power sold in the dayahead market is raised for most of the hours. Furthermore, it is seen that both power sold to or purchased from the adjustment market are increased by exploiting the cooperative trading. The reason for greater involvement of the cooperative trading in both day-ahead and adjustment trading venues could be the higher the flexibility that the cooperative trading model offers compared to the non-cooperative one. Specifically, the more freedom the integration of all resources offers to the coalition gives rise to a higher share of involvement in these two trading venues. For instance, as seen in constraint (31), the higher the coalition's scale, the greater the capacity of involvement in the adjustment trading venue, and thus the higher amount of power sold to or purchased from the adjustment market under the cooperative trading framework. Fig. 4 allows concluding that the cooperative trading results in a higher contribution of resources in trading venues, thereby earning a greater profit.

As stated earlier, the total number of scenarios for simulations was considered $8 \times 5 \times 5 \times 8=1600$. In order to analyze the reliability of the selected scenario set, we carry out a sensitivity analysis on the proposed cooperative trading profit and the computation time under different sizes of the final scenario set, i.e., $|\Omega|=\{324,1600,4900,16900,390625\}$. Note that scenario sets with the size of $324,1600,4900,16900$, and 390625 are associated with scenario trees having the struc-

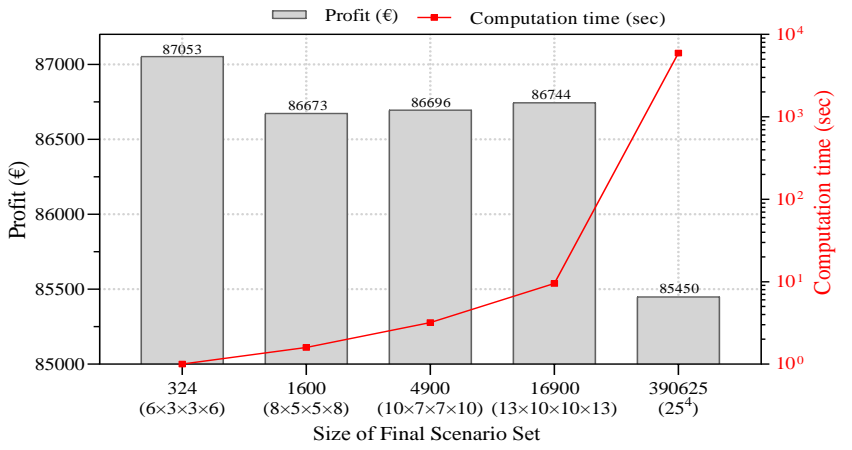

Fig. 4: Sensitivity on the proposed cooperative trading profit and computation time under different sizes of the final scenario set.

ture of $6 \times 3 \times 3 \times 6,8 \times 5 \times 5 \times 8,10 \times 7 \times 7 \times 10,13 \times 10 \times 10 \times 13$, and $25 \times 25 \times 25 \times 25$, respectively. The results are reported in Fig. 4. For the sake of clarity, the format of computation time in Fig. 4 is shown in the power of 10. As observed, the computation time with scenario sets up to 16900 scenarios is under 10 seconds, revealing the proposed architecture's high computational efficiency and tractability. However, all these scenario sets (i.e., 324, 1600, 4900, 16900) results in a distinct profit. For more reliable decision-making over the size of the final scenario set, we construct an enormous scenario tree (here, $25 \times 25 \times 25 \times 25=390625$ ) and treat the resulting profit as the reference point. As seen in Fig. 4, the cooperative trading problem in the enormous scenario tree (390625 scenarios) gives a profit of $€ 85450$ while enduring a high computational burden (5944.6 seconds). It should be noted that enormous scenario trees are rarely leveraged by the decision-makers as the final scenario tree due to their high computational difficulty, still, they provide worthwhile reference points. According to the results, the profit deviation of tractable scenario sets (i.e., $|\Omega|=\{324,1600,4900,16900\}$ ) from the reference profit (€85450) is under $2 \%$, indicating the reliability of the leveraged architecture. Eventually, the scenario tree $8 \times 5 \times 5 \times 8$ is considered as the final scenario set in all simulations since it is highly tractable and has the lowest profit deviation from the reference point.

\section{B. Cost-benefit analysis for the BPP}

Here, we conduct a cost-benefit analysis for the designated BPP to assess the impact of cooperative and non-cooperative trading models along with several other underlying factors on the BPP's payback period, IRR, and NPV. Note that the costbenefit analysis is performed based on the Spanish market data in 2019 [31], and the investment cost of the BPP is considered 
to be $1577.3 € / \mathrm{kW}[22]$. One of the foremost factors to assess the feasibility of a cost-benefit analysis is the payback period. The payback period points out a timeframe that is required to recoup an investment cost and is calculated using the following equation:

$$
\text { Payback Period }=\frac{\text { Total Investment Cost }}{\text { Annualized Total Profit }}
$$

Obviously, the shorter the payback period, the more engaging the investment. Other prominent factors to judge the feasibility of an investment scheme are NPV and IRR. NPV represents the future value of positive cash flows (i.e., benefits) and negative cash flows (i.e., costs) over the lifetime of an investment discounted to the present. The NPV formula is as follows:

$$
\mathrm{NPV}=\sum_{t=0}^{\mathcal{T}} \frac{\digamma_{t}}{(1+\Gamma)^{t}}
$$

where $\mathcal{T}$ is the total number of periods, $\digamma_{t}$ refers to net cash flows at period $t$, and $\Gamma$ stands for the discount rate (or rate of return). As the NPV definition implies, the greater the NPV, the more attractive the investment. The IRR stands for the rate of return (or discount rate) at which the NPV of forthcoming cash flows is equivalent to the investment cost. It can also be defined as the rate of return (or discount rate) at which the overall present value of positive cash flows (i.e., benefits) is equal to the overall present value of negative cash flows (i.e., costs). According to the definition, the IRR is a discount rate at which the NPV is equal to zero, as shown below:

$$
\mathrm{NPV}=\sum_{t=0}^{\mathcal{T}} \frac{\digamma_{t}}{(1+\Gamma)^{t}}=0
$$

The obtained discount rate $(\Gamma)$ from solving the above equation is the IRR. Similar to the NPV, the higher the IRR, the more desirable the investment. Note that Microsoft Excel is utilized for NPV and IRR calculation in this paper. The details of NPV and IRR are outside this paper's scope, whereas they have been thoroughly addressed in [34]. It is worth mentioning that $\mathcal{T}$ is set to 25 years consistent with the economic life of the BPP [22], and discount rates are input data chosen by investors according to the existing situation.

As seen in Table IV, there is no significant difference between the allocated profit to the BPP under different allocation methods in the cooperative approach. There would be thus no considerable difference in BPP's payback period as well as its IRR and NPV under different profit allocation methods. Fig. 5 illustrates the BPP's payback period with different daily available biofuel and various BPP's capacities under cooperative and non-cooperative trading models. As shown in this figure, for all values of BPP's capacity and daily available biofuel, the cooperative trading model obtains a lower payback period. It can also be seen that increasing the BPP's capacity will not lower the payback period on account of the very high investment cost of the BPP. This might be why no BPP with a capacity of more than $50 \mathrm{MW}$ is operating in the Spanish electricity market [31]. Moreover, the impact of daily available biofuel is more significant for larger BPPs. As seen in Fig. 5 ,

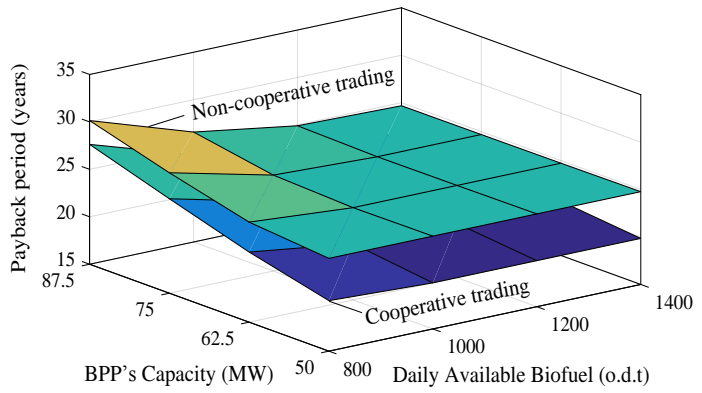

Fig. 5: BPP's payback period with different daily available biofuel and various BPP's capacities.

no more than 1000 o.d.t daily biofuel affects the payback

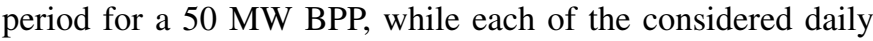
available biofuel (800, 1000, 1200, and 1400 o.d.t) influences the payback period of an 87.5 MW BPP.

With the growing progress in the technology of harvesting and transportation of forestry residues, the biofuel cost is expected to decline [22]. Furthermore, the BPP location is another fundamental factor influencing the biofuel cost since the region where forestry residues are gathered and conveyed to the power plant affects the biofuel cost [30]. In this regard, a cost-benefit analysis for different biofuel costs is carried out under $0 \%, 10 \%, 30 \%$, and $50 \%$ reduction in the biofuel cost. The BPP's payback period and its IRR and NPV for different biofuel costs are displayed in Figs. 6-8. First, it is observed that cooperative trading is a more cost-effective approach when the biofuel cost is high since the difference in the payback periods under different trading schemes is more substantial. This comes from the fact that the integrated operational model of BPP and concentrating solar is a more economical approach when the biofuel cost is high. In fact, integrated energy systems can potentially downplay the role of high fuel prices due to the greater flexibility offered to the entire system. Therefore, in the case of experiencing a relatively high biofuel cost, cooperative trading can act as an up-and-coming alternative for investors to reduce the payback period. Second, it can be observed that with $10 \%, 30 \%$, and $50 \%$ reductions in the biofuel cost, the payback is approximately decreased by $28 \%, 55 \%$, and $67 \%$ under the cooperative framework, and $32 \%, 59 \%$, and $71 \%$ under the non-cooperative framework. The reason lies in the issue that the lower the biofuel cost, the greater the profit, and thus the lower the payback period. Therefore, more and new investments in the BPPs are seen worldwide by decreasing the biofuel cost. Third, Fig. 7 allows concluding that the lower the biofuel cost, the higher the IRR and thus the more interesting the investment. Interestingly, the IRR is an effective measure for investors to analyze the profitability of an investment by comparing the obtained IRR with the minimum acceptable rate of return (or discount rate). If the obtained IRR is greater than the minimum acceptable rate of return, the investment is profitable. For instance, if the minimum acceptable rate of return for an investor is $14 \%$, the only profitable investment would be the cooperative trading under the biofuel cost $=27.325 €$ /o.d.t, as shown in Fig. 7 The NPV of the BPP under two different biofuel costs and for three different discount rates $(0 \%, 5 \%$, and $10 \%)$ are shown in 
This article has been accepted for publication in a future issue of this journal, but has not been fully edited. Content may change prior to final publication. Citation information: DOI10.1109/TSTE.2021.3138777, IEEE Transactions on Sustainable Energy

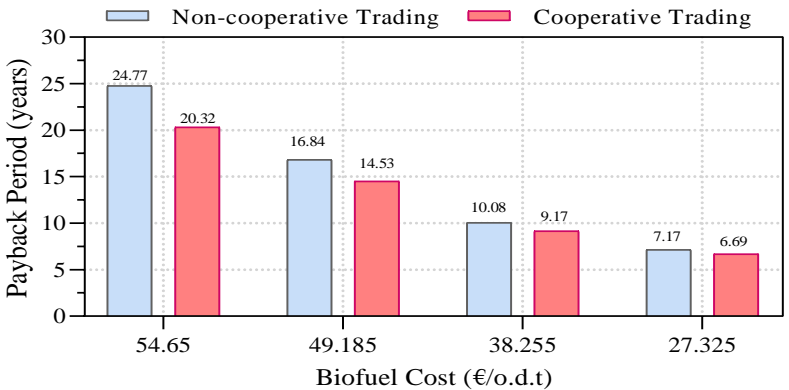

Fig. 6: BPP's payback period under different biofuel costs.

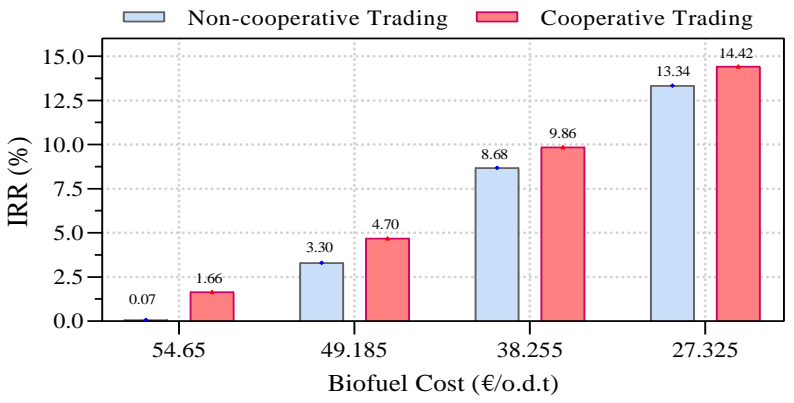

Fig. 7: The IRR of the BPP under different biofuel costs.

Fig. 8. As observed, the highest NPV is experienced for biofuel cost $=27.325 € /$ o.d.t and the lowest discount rate $(0 \%)$. Note that the higher the NPV, the more attractive the investment. The positive values of the NPV reveal that the investment would be profitable, while the negative values indicate that the investment would be loss-making. Thus, for only $10 \%$ discount rate and biofuel cost $=38.255$, the investment is unprofitable. It has to be noted that $\mathcal{T}$ is set to 25 years consistent with the economic life of the BPP [22], and discount rates are input data chosen by investors according to the existing situation.

To further encourage investors to invest in BPPs, several incentive schemes might be offered by policymakers worldwide. For instance, in Spain, the operation and maintenance costs are covered by the contractor who built the power station with the initial designated investment cost [35]. Therefore, the BPPs are no longer responsible for their operation and maintenance costs, which will greatly increase their earnings. To analyze the impact of such an incentive scheme on the BPP's payback period, a cost-benefit analysis is fulfilled without considering operation and maintenance costs. The BPP's payback periods with and without consideration of operation and maintenance costs are reported in Table $\mathrm{V}$. From Table $\mathrm{V}$, it can be noticed that the payback period is remarkably reduced without considering operation and maintenance costs. It is found that the provided incentive scheme in Spain can lessen the BPP's payback period by 7.04 and 5.12 years under non-cooperative and cooperative trading models, respectively.

\section{CONCLUSION}

In this paper, a novel coalitional trading framework with different profit allocation schemes was proposed for a BPP paired with a concentrating solar facility and a wind park. To capture the real-world phenomena of the designated trading problem, all variable cost sources, including operation and maintenance

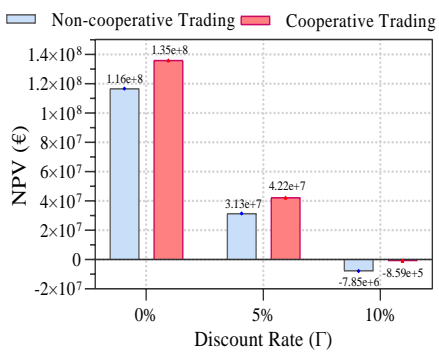

(a) Biofuel cost $=38.255 € /$ o.d.t.

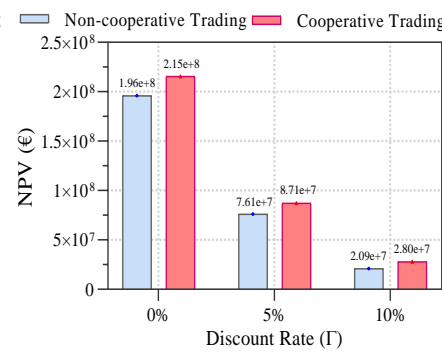

(b) Biofuel cost $=27.325 € /$ o.d.t.
Fig. 8: The NPV of the BPP under two different biofuel costs.

TABLE V: BPP's payback period with and without consideration of operation and maintenance costs.

\begin{tabular}{|c|c|c|}
\hline \multirow{2}{*}{ Trading Model } & \multicolumn{2}{|c|}{ Payback Period (years) } \\
\cline { 2 - 3 } & $c^{\mathrm{BP}}=3.18 € / \mathrm{MWh}$ & $c^{\mathrm{BP}}=0 € / \mathrm{MWh}$ \\
\hline Non-cooperative & 24.77 & 17.73 \\
\hline Cooperative & 20.32 & 15.20 \\
\hline
\end{tabular}

of all units and harvesting and transportation of forestry residue, were considered. The proposed trading problem was formulated as a three-stage stochastic setting encompassing diverse uncertain origins. Additionally, a cost-benefit analysis was performed for the BPP to assess several primary factors on the BPP's payback period. From case studies, we can draw the following conclusions: 1) The proposed cooperative trading framework outperforms the non-cooperative trading model by providing a $4.55 \%$ profit gain in a representative day; 2) The performance of profit allocation methods in terms of the profit allocation to each coalition member is relatively similar; 3) Cooperative trading substantially outperforms the non-cooperative one in the case of BPP's payback period; 4) By increasing the BPP's capacity, the payback period is also starting to rise; 5) The impact of daily available forestry residue on the BPP's payback period is limited, especially for smaller-scale power plants; 6) Concerning high biofuel costs, the coalitional trading model is more cost-effective in terms of the BPP's payback period, while the impact of cooperative trading in low biofuel costs is not significant compared to the non-cooperative one; 7) The incentive scheme offered in Spain could substantially reduce the BPP's payback period.

\section{REFERENCES}

[1] C. S. Lai, Y. Jia, L. L. Lai, Z. Xu, M. D. McCulloch, and K. P. Wong, "A comprehensive review on large-scale photovoltaic system with applications of electrical energy storage," Renew. Sustain. Energy Rev., vol. 78, pp. 439-451, 2017.

[2] E. Commissie, "A Roadmap for moving to a competitive low carbon economy in 2050," Eur. Commissie, Brussel, 2011.

[3] A. Hajebrahimi, I. Kamwa, M. Abdelaziz, and A. Moeini, "ScenarioWise Distributionally Robust Optimization for Collaborative Intermittent Resources and Electric Vehicle Aggregator Bidding Strategy," IEEE Trans. Power Syst., 2020.

[4] S. A. Hosseini, J.-F. Toubeau, Z. De Grève, and F. Vallée, "An advanced day-ahead bidding strategy for wind power producers considering confidence level on the real-time reserve provision," Appl. Energy, vol. 280, p. 115973, 2020.

[5] M. K. AlAshery, D. Xiao, and W. Qiao, "Second-Order Stochastic Dominance Constraints for Risk Management of a Wind Power Producer's Optimal Bidding Strategy," IEEE Trans. Sustain. Energy, 2019. 
This article has been accepted for publication in a future issue of this journal, but has not been fully edited. Content may change prior to final publication. Citation information: DOI10.1109/TSTE.2021.3138777, IEEE Transactions on Sustainable Energy

[6] X. Dai, Y. Li, K. Zhang, and W. Feng, "A robust offering strategy for wind producers considering uncertainties of demand response and wind power," Appl. Energy, vol. 279, p. 115742, 2020.

[7] G. He, Q. Chen, C. Kang, and Q. Xia, "Optimal Offering Strategy for Concentrating Solar Power Plants in Joint Energy, Reserve and Regulation Markets," IEEE Trans. Sustain. Energy, vol. 7, no. 3, pp. 1245-1254, 2016

[8] D. Yu, A. G. Ebadi, K. Jermsittiparsert, N. H. Jabarullah, M. V. Vasiljeva, and S. Nojavan, "Risk-constrained Stochastic Optimization of a Concentrating Solar Power Plant," IEEE Trans. Sustain. Energy, 2019.

[9] Y. Wang, S. Lou, Y. Wu, M. Miao, and S. Wang, "Operation strategy of a hybrid solar and biomass power plant in the electricity markets," Electr. Power Syst. Res., vol. 167, pp. 183-191, 2019.

[10] I. Blanco, A. N. Andersen, D. Guericke, and H. Madsen, "A novel bidding method for combined heat and power units in district heating systems," Energy Syst., pp. 1-20, 2019.

[11] Y. Fang and S. Zhao, "Look-ahead bidding strategy for concentrating solar power plants with wind farms," Energy, p. 117895, 2020.

[12] H. Khaloie, M. Mollahassani-pour, and A. Anvari-Moghaddam, "Optimal Behavior of a Hybrid Power Producer in Day-Ahead and Intraday Markets: A Bi-Objective CVaR-Based Approach," IEEE Trans. Sustain. Energy, p. 1, 2020.

[13] A. Jamali et al., "Self-scheduling approach to coordinating wind power producers with energy storage and demand response," IEEE Trans. Sustain. Energy, 2019.

[14] H. Khaloie, F. Vallée, C. S. Lai, J.-F. Toubeau, and N. D. Hatziargyriou, "Day-ahead and Intraday Dispatch of an Integrated BiomassConcentrated Solar System: A Multi-Objective Risk-Controlling Approach," IEEE Trans. Power Syst., 2021.

[15] R. Zhang, T. Jiang, F. F. Li, G. Li, H. Chen, and X. Li, "Coordinated Bidding Strategy of Wind Farms and Power-to-Gas Facilities using a Cooperative Game Approach," IEEE Trans. Sustain. Energy, 2020.

[16] Z. Wu, M. Zhou, J. Wang, E. Du, N. Zhang, and G. Li, "Profit-Sharing Mechanism for Aggregation of Wind Farms and Concentrating Solar Power," IEEE Trans. Sustain. Energy, 2020.

[17] B. Li, X. Wang, M. Shahidehpour, C. Jiang, and Z. Li, "Robust bidding strategy and profit allocation for cooperative DSR aggregators with correlated wind power generation," IEEE Trans. Sustain. Energy, vol. 10, no. 4, pp. 1904-1915, 2018.

[18] H. T. Nguyen and L. B. Le, "Sharing Profit from Joint Offering of a Group of Wind Power Producers in Day Ahead Markets," IEEE Trans. Sustain. Energy, 2018.

[19] L. L. Lai, Power system restructuring and deregulation: trading, performance and information technology. John Wiley \& Sons, 2001.

[20] A. J. Conejo, M. Carrión, and J. M. Morales, Decision Making Under Uncertainty in Electricity Markets, vol. 1. Boston, MA: Springer US, 2010.

[21] "Curtis-Teixeiro Biomass Plant (A Coruña, Galicia, Spain) FuturENVIRO - Revista técnica bilingüe de medio ambiente." https://futurenviro.es/en/curtis-teixeiro-biomass-plant-a-coruna-galiciaspain/ (accessed Jan. 25, 2021).

[22] IRENA - International Renewable Energy Agency, "Power Generation Biomass for Wind Power," Biomass Power Gener, no. Volume 1: Power Sector, Issue 1/5, p. 274, 2012.

[23] J.-F. Toubeau, J. Bottieau, F. Vallée and Z. De Grève, ”Deep LearningBased Multivariate Probabilistic Forecasting for Short-Term Scheduling in Power Markets," in IEEE Transactions on Power Systems, vol. 34, no. 2, pp. 1203-1215, March 2019.

[24] H. Khaloie, A. Anvari-Moghaddam, N. Hatziargyriou, and J. Contreras, "Risk-constrained self-scheduling of a hybrid power plant considering interval-based intraday demand response exchange market prices," J. Clean. Prod., vol. 282, p. 125344, 2021.

[25] H. Khaloie, A. Anvari-Moghaddam, J. Contreras, and P. Siano, "RiskInvolved Optimal Operating Strategy of a Hybrid Power Generation Company: A Mixed Interval-CVaR Model," Energy, p. 120975, 2021.

[26] S. Tijs, "Bounds for the core of a game and the t-value," Game theory Math. Econ., pp. 123-132, 1981.

[27] D. Schmeidler, "The nucleolus of a characteristic function game," SIAM J. Appl. Math., vol. 17, no. 6, pp. 1163-1170, 1969.

[28] D. Songhuai, Z. Xinghua, M. Lu, and X. Hui, "A novel nucleolus-based loss allocation method in bilateral electricity markets," IEEE Trans. Power Syst., vol. 21, no. 1, pp. 28-33, 2006.

[29] L. S. Shapley, "A value for n-person games," Contrib. to Theory Games, vol. 2 , no. 28 , pp. $307-317,1953$.
[30] S. T. Fernández, J. P. P. Sánchez, and A. J. G. Trashorras, "Analysis of forest residual biomass potential for bioenergy production in Spain," Clean Technol. Environ. Policy, vol. 18, no. 1, pp. 209-218, 2016.

[31] "Bienvenido - ESIOS electricidad . datos . transparencia." https://www.esios.ree.es/es (accessed Feb. 12, 2021).

[32] "SCENRED2." https://www.gams.com/latest/docs/T_SCENRED2.html (accessed Feb. 07, 2021).

[33] A. Churkin, J. Bialek, D. Pozo, E. Sauma, and N. Korgin, "Review of Cooperative Game Theory applications in power system expansion planning," Renew. Sustain. Energy Rev., vol. 145, p. 111056, 2021.

[34] C. L. Dudley, "A note on reinvestment assumptions in choosing between net present value and internal rate of return," J. Finance, vol. 27, no. 4 pp. 907-915, 1972.

[35] "ACCIONA Industrial e IMASA construirán y mantendrán la planta de biomasa de Greenalia en Teixeiro, La Coruña." https://www.accionaindustrial.com/es/salaprensa/noticias/2018/agosto/acciona-industrial-eimasa-construiran-y-mantendran-la-planta-de-biomasa-de-greenalia-enteixeiro-la-coruna/ (accessed Feb. 12, 2021).

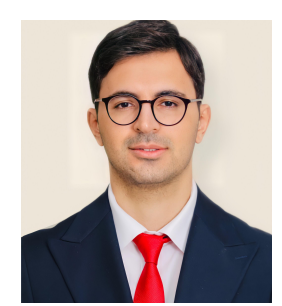

Hooman Khaloie received the M.Sc. degree (First Class Hons.) from Shahid Bahonar University of Kerman, Kerman, Iran, in 2019. During 2019 and 2021, he was a Research Assistant at Kerman Regional Electric Company, Iran's Ministry of Energy. He received the Outstanding Reviewer Award from the IEEE Transactions on Power Systems in 2020. His research interests include electricity markets, financial risk assessment, integrated energy systems, and operations research.

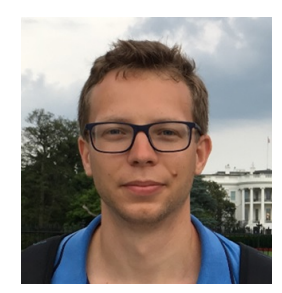

Jean-François Toubeau (Member, IEEE) received the degree in civil electrical engineering, and the $\mathrm{Ph} . \mathrm{D}$. degree in electrical engineering, from the University of Mons (Belgium) in 2013 and 2018, respectively. $\mathrm{He}$ is currently a postdoctoral researcher of the Belgian Fund for Research (F.R.S/FNRS) within the "Power Systems and Markets Research Group" of the same University. His research mainly focuses on bridging the gap between machine learning and decision-making in modern power systems.

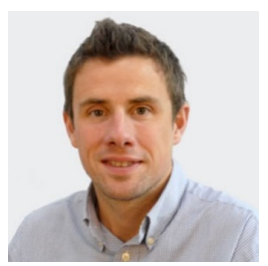

François Vallée (Member, IEEE) received the degree in civil electrical engineering and the Ph.D. degree in electrical engineering from the Faculty of Engineering, University of Mons, Belgium, in 2003 and 2009, respectively. He is currently a Professor and leader of the "Power Systems and Markets Research Group" at the University of Mons. His Ph.D. work has been awarded by the SRBE/KBVE Robert Sinave Award in 2010. His research interests include PV and wind generation modeling for electrical system reliability studies in presence of dispersed 
This article has been accepted for publication in a future issue of this journal, but has not been fully edited. Content may change prior to final publication. Citation information: DOI10.1109/TSTE.2021.3138777, IEEE Transactions on Sustainable Energy

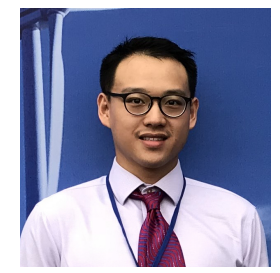

Chun Sing Lai (Senior Member, IEEE) received the B.Eng. (First Class Hons.) in electrical and electronic engineering from Brunel University London, London, U.K., in 2013, and the D.Phil. in engineering science from the University of Oxford, Oxford, U.K., in 2019. He is currently a Lecturer with the Department of Electronic and Electrical Engineering, Brunel University London. From 2018 to 2020, he was an Engineering and Physical Sciences Research Council Research Fellow with the School of Civil Engineering, University of Leeds, Leeds, U.K. His current research interests are in power system optimization and data analytics. Dr. Lai was the Secretary of the IEEE Smart Cities Publications Committee, the Acting Editor-in-Chief of IEEE Smart Cities Newsletters, and Publications Co-Chair for 2020 and 2021 IEEE International Smart Cities Conference. He is the Vice-Chair of the IEEE Smart Cities Publications Committee. He is the Working Group Chair for IEEE P2814 Standard, and the Chair of the IEEE SMC Intelligent Power and Energy Systems Technical Committee. He is an IET Member and a Chartered Engineer.

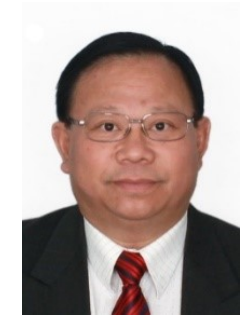

Loi Lei Lai (Life Fellow, IEEE) received the B.Sc. (First Class Hons.), Ph.D., and D.Sc. degrees in electrical and electronic engineering from the University of Aston, Birmingham, UK, and City, University of London, London, UK, in 1980, 1984, and 2005, respectively.

Professor Lai is currently a University Distinguished Professor with Guangdong University of Technology, Guangzhou, China. He was a Pao Yue Kong Chair Professor with Zhejiang University, Hangzhou, China, and the Professor and Chair of Electrical Engineering with City, University of London. His current research areas are in smart cities and smart grid. Professor Lai was awarded an IEEE Third Millennium Medal, the IEEE Power and Energy Society (IEEE/PES) UKRI Power Chapter Outstanding Engineer Award in 2000, the IEEE/PES Energy Development and Power Generation Committee Prize Paper in 2006 and 2009, the IEEE/SMCS Outstanding Contribution Award in 2013 and 2014, the Most Active Technical Committee Award in 2016, and his research team has received a Best Paper Award in the IEEE International Smart Cities Conference in October 2020.

Professor Lai is an Associate Editor of the IEEE Transactions on Systems, Man, and Cybernetics: Systems, Editor-in-Chief of the IEEE Smart Cities Newsletter, a member of the IEEE Smart Cities Steering Committee and the Chair of the IEEE Systems, Man, and Cybernetics Society (IEEE/SMCS) Standards Committee. He was a member of the IEEE Smart Grid Steering Committee; the Director of Research and Development Center, State Grid Energy Research Institute, China; a Vice President for Membership and Student Activities with IEEE/SMCS; and a Fellow Committee Evaluator for the IEEE Industrial Electronics Society. He is a Fellow of IET. 